\title{
Microflora Modulation of Motility
}

\author{
Eamonn M M Quigley
}

Alimentary Pharmabiotic Centre, University College Cork, Cork, Ireland

That gastrointestinal motility can influence the gut microbiota has been known for decades and the clinical consequences of impaired motility, in terms of the bacterial population of the small intestine, amply illustrated by the syndrome of small intestinal bacterial overgrowth which so commonly accompanies diffuse intestinal motility disorders. As the importance of the microbiota to homeostasis in health and to a variety of disease states is increasingly appreciated and as the full diversity and biology of this "hidden organ" have been revealed by molecular methodologies, the true nature of the interaction between the microbiota and motility is being re-examined and the complexity of this relationship exposed. In health, as well as in disease states, this is a truly bi-directional relationship: not only can gut motor patterns influence the microbiota but changes in the microbiota can exert profound influences on gut sensori-motor function.

(J Neurogastroenterol Motil 2011;17:140-147)

\section{Key Words}

Gastrointestinal motility; Irritable bowel syndrome; Metagenome

\section{Introduction}

The gut microbiota (formerly referred to as the gut flora) and its interactions, both symbiotic and pathogenic, with the host, have become one of the hottest areas in biomedical science. ${ }^{1}$ This explosion in research and knowledge has its origins in both the laboratory and the clinic. While, in the laboratory, the application of modern molecular techniques, such as genomics and metabolomics, has revealed the true size, genetic diversity and metabolic complexity of the bacterial components of the microbiota, ${ }^{2,3}$ clinical observations have highlighted the importance of the microbiota and host-microbe interactions in health and disease. ${ }^{1,4}$ It is now acknowledged that the number of bacteria within the gut is about 10 times that of all of the cells in the human body, that the microbiome contains much more genetic material than the host and that it represents a formidable metabolic "organ," not only being capable of extracting calories from food components impenetrable to the host but also elaborating a large array of biologically important compounds ranging from short-chain fatty acids and gases to antibiotics and neuro-modulatory substances. Techniques based on 16S rRNA sequences have revealed that the diversity of the human microbiota is much greater than previously thought and that the majority of bacterial sequences correspond to unculturable sequences and novel bacteria. ${ }^{3}$

\section{Motility-Microbiota Interactions: The Basics -}

\section{The Development of the Microbiota}

Interactions between the microbiota and motility may be evident from the earliest stages of life. The developmental aspects of

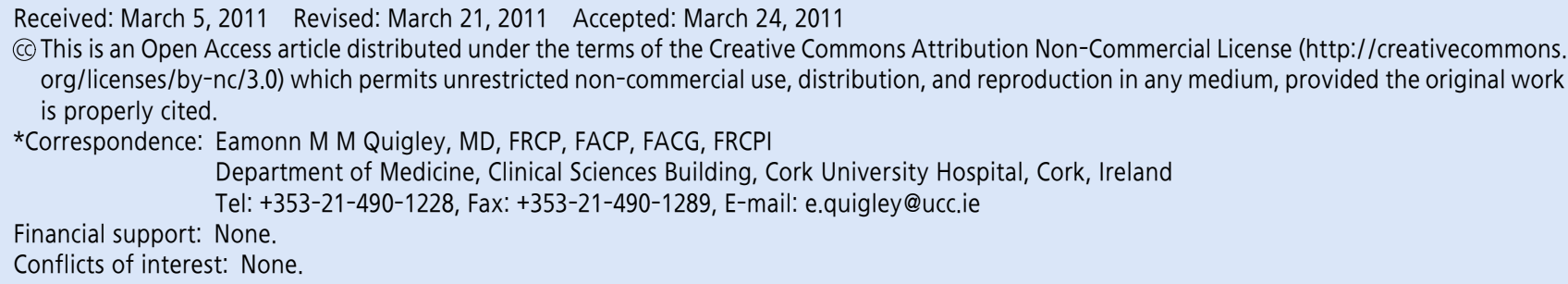


the microbiota are also of clinical interest, given the importance of early life events to the pathophysiology of disorders such as irritable bowel syndrome (IBS). At birth, the entire intestinal tract is sterile; bacteria enter the gut with the first feed. ${ }^{5}$ Following infancy, the composition of the intestinal microbiota remains relatively constant thereafter. Motor patterns, motor responses and enteric neuromuscular physiology also evolve over this time period. ${ }^{6-8}$ That the phenomena of motor and microbiota maturation are related is most vividly illustrated by studies in germ-free animals ${ }^{9}$; not only are motor patterns disrupted in these animals but enteric neural and muscular function and morphology are abnormal. When disturbed, the microbiota has a remarkable capacity to restore itself and to return to exactly the same state as it was before. ${ }^{1}$ Whether this restorative capacity is equally evident in the neonate and infant remains to be defined; it is possible that disturbances to the microbiota at this formative stage in its evolution may have more permanent consequences. It has recently been suggested, for example, that antibiotic use in early childhood is a significant risk factor for the development of inflammatory bowel disease in later life. ${ }^{10}$

\section{Motor Patterns and the Microbiota}

Relationships between motility and the microbiota are evident in the normal intestine. Indeed, it is because of the presence of such normal motility patterns as peristalsis and the migrating motor complex, acting together with the antimicrobial effects of gastric acid, that the stomach and proximal small intestine contain relatively small numbers of bacteria in healthy subjects; jejunal cultures may not detect any bacteria in as many as $33 \%{ }^{11,12}$ The relationship between the integrity of the migrating motor complex and the absence of small intestinal bacterial overgrowth (SIBO) was, in fact, first described in man almost 35 years ago by Vantrappen et al. ${ }^{13}$ The microbiology of the terminal ileum represents a transition zone between the jejunum containing predominantly facultative anaerobes and the dense population of anaerobes found in the colon. Bacterial colony counts may be as high as $1 \times 10^{9} \mathrm{CFU} / \mathrm{mL}$ in the terminal ileum immediately proximal to the ileocecal valve, with a predominance of Gram-negative organisms and anaerobes. On crossing into the colon, the bacterial concentration and variety of the enteric microbiota change dramatically. Specialized motor patterns of the terminal ileum ${ }^{14,15}$ (where the migrating motor complex is less evident in $\operatorname{man}^{15}$ ), as well as the physiological and bio-mechanical properties of the ileo-colonic junction, ${ }^{16,17}$ no doubt contribute to these ileo-colonic bacterial gradients. Concentrations as high as $1 \times 10^{12}$
$\mathrm{CFU} / \mathrm{mL}$ may be found in the colon; comprised mainly of anaerobes such as Bacteroides, Porphyromonas, Bifidobacterium, Lactobacillus and Clostridium, with anaerobic bacteria outnumbering aerobic bacteria by a factor of 100-1,000:1. ${ }^{4}$ The predominance of anaerobes in the colon reflects the fact that oxygen concentrations in the colon are very low; the microbiota has simply adapted to survive in this hostile environment!

\section{Luminal Versus Mucosal Microbiota}

At any given level of the gut, the composition of the microbiota also demonstrates variation along its diameter with certain bacteria tending to be adherent to the mucosal surface while others predominate in the lumen ${ }^{18}$; studies which rely on the analysis of the fecal microbiota alone may miss the impact of an important population of organisms: those closely adherent to the mucosa. ${ }^{3}$ Indeed, there is considerable interest in the potential role of these juxta-mucosal organisms in the initiation and/or perpetuation of inflammation in inflammatory bowel disease. ${ }^{19,20}$ Motility, including the contractile activity of both the longitudinal and circular muscle layers could well be seen to play a role in determining the relative numbers and diversity of bacteria in the center and at the periphery of the lumen.

\section{"Normal" Variations in the Microbiota}

In humans, the composition of the microbiota is also influenced by age, diet and socio-economic conditions and, above all, by the use of antibiotics; factors that may also influence motor patterns. Whether these changes in the microbiota and motility are related or independent events remains to be defined. There is a suggestion that SIBO occurring in the elderly in the absence of any other identifiable cause may be consequent upon age-related changes in small intestinal motility. ${ }^{21}$ Given these "normal" variations in the microbiota, studies purporting to identify alterations in the microbiota in disease states must, accordingly, be interpreted with great care and some degree of skepticism.

\section{Motility and the Microbiota; Who Is in Charge?}

Motility and the microbiota are clearly associated; the question is which is calling the tune? The conventional doctrine is that motor patterns influence the size, location and diversity of the microbiota; thus the clinical association between a variety of motor disorders and SIBO. That the microbiota can influence motor patterns has been vividly illustrated, not only by the aforementioned studies in the germ-free animal, but also in experimental models of the short bowel syndrome where resection 
of extensive portions of normal, more distal small intestine result in profound motor disruption in the more proximal remnant. ${ }^{22}$ These dramatic motor changes occur in the context of a dramatic increase in the bacterial population, as well as the concentration of a bacterial product, short chain fatty acids, in the remnant. ${ }^{23-25}$

These observations make teleological sense: motility seeks to rid the gut of a presence that it senses to be pathogenic. Extensive studies in a murine model of enteric nematode infestation have revealed, in great detail, the physiological, morphological and ultrastructrual changes that can result from transient infestation and that appear to be mediated via the immune response; the net effect being the expulsion of the invader. ${ }^{26}$

Barbara et al, ${ }^{9}$ in their elegant review, identified 3 mechanisms whereby the microbiota could influence gut motor function: (1) through the release of bacterial substances or end-products of bacterial fermentation, (2) via intestinal neuroendocrine factors $^{27}$ and (3) indirectly through the effects of mediators released by the gut immune response.

A variety of bacterial components and products have been shown to affect motility. ${ }^{9}$ Indeed, the potential for short-chain fatty acids and another bacterial metabolite, deconjugated bile salts, to generate potent motor responses has been amply demonstrated in both animal models ${ }^{28,29}$ and man. ${ }^{30,31}$ The bile salt effects may well be relevant to bile salt diarrhea, a phenomenon that has recently enjoyed a renaissance as a factor in the etiology of diarrhea-predominant IBS $^{32}$ and has even led to the exploration of bile salts as a therapeutic intervention for constipation-predominant IBS. ${ }^{33}$ In other studies, modifications in the microbiota induced by dietary changes have been shown to alter motor patterns in the duodenum and jejunum. ${ }^{34}$ The fermentation of unabsorbed carbohydrates is a function of the colonic microbiota; quantitative changes in gas volume could be seen to elicit reflex responses induced by distension whereas qualitative changes, such as an overproduction of methane, have been shown to directly inhibit motor activity. ${ }^{35}$ Abnormal gas handling has been identified as a factor in the pathogenesis of bloating and distension in irritable bowel syndrome ${ }^{36}$; how the microbiota contributes to this phenomenon is unknown. That a modification of the microbiota can lead to changes in colonic fermentation in man has been amply demonstrated in studies which, either by employing a prebiotic which selectively increased the numbers of bifidobacteria $^{37}$ or by directly supplementing bifidobacteria, ${ }^{38}$ reduced colonic fermentation. Changes in fermentation influence motor function, not just in the colon, but at sites as distant as the lower esophageal sphincter ${ }^{39}$ and stomach. ${ }^{40}$
While microbial effects on gut mucosal neuroendocrine function have been recognized for some time, ${ }^{27}$ it has only been recently that the ability of components of the microbiota to elaborate molecules that have the potential to influence gut motor and sensory function has been recognized. Certain species have been shown to elaborate neurotransmitter peptides, as well as the inhibitory neurotransmitter gas, nitric oxide. ${ }^{41}$ Perturbation of the flora by an antibiotic has been shown to increase substance $\mathrm{P}$ immunoreactivity and induce hypersensitivity in the colon ${ }^{42}$; in contrast, certain commensal strains have the capacity to modulate intestinal pain through the induction of opioid and cannabinoid receptors. $^{43}$

The microbiota and the host enjoy many complex interactions which include influences on the gut epithelium and its integrity, the mucosal and systemic immune systems and the gutbrain axis. Each of these areas has been the subject of extensive research; suffice it to say that effects of the microbiota on the mucosal barrier, immune responses and neuroendocrine responses could have direct and indirect impacts on the function and, even, the morphology of gut muscle and nerve. Such studies have illustrated relationships between mucosal inflammation and gut motor and sensory functions, ${ }^{44}$ the ability of modifications of the microbiota to influence gut barrier function ${ }^{45-47}$ and the consequences to the host of deficits in the latter. ${ }^{48}$ Given the current focus on the possible contributions of inflammation to motor dysfunction in a variety of dysmotility and functional disorders, these microbe-immune responses have attracted considerable attention.

\section{Motility-Microbiota Interactions: Clinical Implications}

While the list of gastrointestinal and non-gastrointestinal disorders that may be related to some disturbance in the microbiota and/or the microbiota-host interaction is lengthy, I will illustrate the bidirectionality of this relationship, so evident in laboratory studies, with 2 clinical entities: SIBO and IBS.

\section{Small Intestinal Bacterial Overgrowth}

Although SIBO is usually defined in quantitative terms, as the number of colony forming units per $\mathrm{mL}$, the interpretation of such definitions must be mindful, firstly, of the location, in the intestine, from where the sample was obtained and, secondly, of the fact that the majority of bacterial species in the gut remain unculturable. Alternatively, the diagnosis may be based on the presence of such consequences of SIBO as malabsorption, com- 
bined with a positive result from such noninvasive diagnostic methods as breath tests. These reservations notwithstanding, SIBO is usually, and pending the validation of a more accurate methodology based on molecular microbiology, defined as the presence of $>1 \times 10^{5} \mathrm{CFU}$ per $\mathrm{mL}$ of bacteria in the proximal small bowel. $^{49}$

Dysmotility predisposes to an increase in colonic bacteria in the small intestine; diseases resulting in impaired intestinal motility are, therefore, likely to have SIBO as a complication. Scleroderma and diabetic gastroenteropathy are among the more common disorders that exemplify the occurrence of SIBO in the context of impaired motility; indeed, SIBO may complicate any of the many conditions that lead to the syndrome of chronic intestinal pseudo-obstruction. Reflecting the predilection of small intestinal myopathic disorders to SIBO, this complication has been documented in $43 \%-56 \%$ of patients with scleroderma. ${ }^{50,51}$ The prevalence of SIBO was higher among those with a higher global symptom score and, especially, among those with a high score for digestive symptoms. Other risk factors for SIBO included the presence of diarrhea and constipation. Eradication of SIBO, successful in 52\%-73\%, resulted in symptom improvement. $^{50,51}$ SIBO is associated with small intestinal diverticulosis. Diverticula in the jejunum occur in $0.07 \%$ to $2 \%$ of the population, are twice as frequent in men and are observed predominantly among those over 60 years of age. Morphological studies suggest that disorders of intestinal motility such as progressive systemic sclerosis, visceral myopathies and neuropathies play an important role in the formation of the small bowel diverticula. ${ }^{52}$

However, by far the greatest controversy related to SIBO over the past decade and a half has been the proposal that SIBO is linked to IBS. The initial reports from Pimentel et al, ${ }^{53,54}$ using the lactulose breath test, documented SIBO in $84 \%$ of their patients with IBS. Normalization of the lactulose breath test in this group, by use of neomycin, resulted in a significant improvement in IBS symptoms. Furthermore, methane excretion, on breath testing, was highly associated with a constipation-predominant subgroup of IBS. The same group found that their IBS patients with SIBO exhibited both a lower number and duration of phase III of the MMC, on antroduodenal manometry, in comparison to control subjects. Significant concerns have been raised regarding the validity of this association. ${ }^{55-59}$ In an important systematic review and meta-analysis of the link between SIBO and IBS, Ford et $\mathrm{al}^{60}$ drew attention to the impact of test modality on SIBO prevalence, the average prevalence of SIBO on breath tests being $54 \%$; in sharp contrast to a mean prevalence of just $4 \%$ for jejunal aspirate cultures. ${ }^{60}$ These authors also drew attention to the impact of diagnostic criteria, which varied considerably between studies, on study outcome. ${ }^{60}$ To muddy the waters further it has been suggested that the apparent link between SIBO and IBS may represent the impact of the proton pump inhibitors which are prescribed so readily in this patient population. ${ }^{61}$ My personal opinion is that, while some patients with SIBO may present with IBS-type symptoms, SIBO is not a major contributor to the pathogenesis of IBS, in general. Furthermore, I believe that the modest improvement in IBS symptoms that has now been reported with some consistency in IBS with antibiotic therapy may owe more to the effects of these agents on the colonic flora rather than SIBO. ${ }^{62-64}$ This is supported both by the presence, in the study by Sharara et al, ${ }^{65}$ of a symptomatic response to antibiotic therapy among subjects with a normal baseline breath test and by the very recent demonstration that accelerated small bowel transit, and not SIBO, was the major contributor to positive lactulose breath tests in IBS. ${ }^{66}$ These and other considerations have led to a serious re-evaluation of the status of SIBO in IBS. ${ }^{67}$

\section{Irritable Bowel Syndrome}

Approximately $10 \%-20 \%$ of adults in the West have symptoms consistent with IBS. A combination of visceral hypersensitivity, smooth muscle spasm and impairment of central pain processing likely contribute to the pain associated with IBS, while altered intestinal motility underlies the disordered defecation experienced by some patients with IBS.

Over the decades, various theories have been advanced to explain the pathogenesis of symptoms in the IBS patient, including dysmotility, visceral hypersensitivity and the psyche. The concept of the gut brain axis, emphasizing the interactivity at sensory, motor and neuro-endocrine levels, between the brain and the gut has provided a useful paradigm to encompass these diverse factors. This axis has been extended, by some, to include interaction between the gut flora (or microbiota), the immune system (both mucosal and systemic), the gut and the brain (the gut-brain-immune-microbial axis). In this scenario, interactions between the flora (be it normal and disturbed) and the mucosal immune system (gut-, or mucosa-associated lymphoid tissue) lead to the release of peptides and other neuro-active substances which generate, both locally and systemically, the neuro-muscular events that typify IBS and generate the patient's symptoms. One of the most convincing pieces of evidence supporting the involvement of the microbiota in IBS is the phenomenon of post-infectious IBS. We are now beginning to see real data to directly support 
the concept of post-infectious IBS. The occurrence of IBS following episodes of bacteriologically-confirmed gastroenteritis has now been documented in several studies. Thabane et $\mathrm{al}^{68}$ concluded that the overall risk for the development of IBS was increased 6-fold following an episode of bacterial gastro-enteritis with younger subjects, those who have prolonged fever during the episode of gastroenteritis and those who suffer from anxiety or depression being at greatest risk.

Post-infectious IBS may explain only a minority of cases of IBS but it does illustrate a clear link between exposure to an environmental agent, inflammation and IBS in predisposed individuals. Thus, Gwee et al ${ }^{69}$ demonstrated an increase in the number of chronic inflammatory cells in the rectal mucosa among those patients exposed to bacterial gastroenteritis who had developed IBS. Others have demonstrated a persisting increase in rectal mucosal enteroendocrine cells, T lymphocytes and gut permeability in patients with post-dysenteric IBS. ${ }^{70,71}$ These observations are important as they indicate a relationship between perturbations of the microbiota, mucosal inflammation and IBS, an hypothesis that is amply supported by data from studies in experimental animal models. In IBS, in general, evidence for a role for the microbiota can also be inferred from observations suggesting the presence of immune activation and subtle levels of inflammation in IBS. Such evidence was first provided by Chadwick et $\mathrm{al}^{72}$ who demonstrated microscopic inflammation or immune activation in among diarrhea-predominant IBS. Subsequent studies have provided further evidence of $\mathrm{T}$ lymphocyte $^{73,74}$ and mast cell activation ${ }^{75-78}$ in the mucosa in IBS; others have demonstrated an extension of inflammation into the myoneural compartments ${ }^{79}$ and others still cytokine profiles in peripheral blood mononuclear cells ${ }^{80,81}$ and serum ${ }^{82}$ compatible with a pro-inflammatory state.

It is attractive to suggest that these immunological changes could result from exposure to an exogenous (such as bacterial) antigen challenge. ${ }^{83,84}$ That IBS patients may be predisposed to an, albeit contained, inflammatory response to luminal triggers is, indeed, supported by the finding of polymorphisms in genes that encode for the production of anti-inflammatory cytokines among IBS patients ${ }^{85,86}$ and by the very recent description of high titers of anti-flagellin antibodies in serum derived from IBS patients. ${ }^{87,88}$ Further, more direct, support for this hypothesis comes from the demonstration of elevated levels of defensins in fecal fluid ${ }^{89}$ and of upregulation of Toll-like receptor $4^{90}$ in IBS.

So is there direct evidence for changes in the microbiota in IBS? While, in the past, various studies had suggested the pres- ence of qualitative changes in the colonic flora in IBS patients; a relative decrease in the population of bifidobacteria being the most consistent finding. ${ }^{91,92}$ Several factors limit the interpretability of these studies, including the unrepresentative nature of the fecal flora, a failure to describe those bacterial populations that may be adherent to the mucosal surface and, above all, the recognition that a very significant proportion of the colonic microbiota cannot be identified by conventional culture methods. Molecular methods are now being applied to this complex issue and have, indeed, confirmed that IBS patients, regardless of sub-type, do exhibit a fecal flora that is clearly different from control subjects. ${ }^{18,93-95}$ The precise nature of these differences and their potential to disturb mucosal or myoneural function, in the gut wall, or induce local or systemic immune responses, remains to be defined.

\section{Conclusion}

In the past, the relationship between motility and the microbiota was viewed as unidirectional with motility maintaining the sterility of the upper gastrointestinal tract and dysmotility predisposing to small intestinal bacterial overgrowth. This narrow concept has been cast aside with the recognition of the ability of the microbiota to influence the development of normal motor patterns and the potential for disturbances in the microbiota to elicit motor responses or, if sustained, to lead to sensori-motor dysfunction and motility and, perhaps, functional disorders such as IBS. Accordingly, therapeutic approaches which modify the microbiota, including prebiotics, probiotics and antibiotics are being explored in IBS.

\section{References}

1. Guarner F, Malagelada JR. Gut flora in health and disease. Lancet 2003;361:512-519.

2. Hattori M, Taylor TD. The human intestinal microbiome: a new frontier of human biology. DNA Res 2009;16:1-12.

3. Eckburg PB, Bik EM, Bernstein CN, et al. Diversity of the human intestinal microbial flora. Science 2005;308:1635-1638.

4. Neish AS. Microbes in gastrointestinal health and disease. Gastroenterology 2009;136:65-80.

5. Palmer C, Bik EM, DiGiulio DB, Relman DA, Brown PO. Development of the human infant intestinal microbiota. PloS Biol 2007;5:e177.

6. Berseth CL. Gestational evolution of small intestine motility in preterm and term infants. J Pediatr 1989;115:646-651.

7. Berseth CL. Gastrointestinal motility in the neonate. Clin Perinatol 1996;23:179-190. 
8. Hassan BB, Butler R, Davidson GP, et al. Patterns of antropyloric motility in fed healthy preterm infants. Arch Dis Child Fetal Neonatal Ed 2002;87:F95-F99.

9. Barbara G, Stanghellini V, Brandi G, et al. Interactions between commensal bacteria and gut sensorimotor function in health and disease. Am J Gastroenterol 2005;100:2560-2568.

10. Shaw SY, Blanchard JF, Bernstein CN. Association between the use of antibiotics in the first year of life and pediatric inflammatory bowel disease. Am J Gastroenterol 2010;105:2687-2692.

11. Quigley EM. Small intestinal motor activity - its role in gut homeostasis in health and disease. Q J Med 1987;65:799-810.

12. Quigley EM, Abu-Shanab A. Small intestinal bacterial overgrowth. Infect Dis Clin North Am 2010;24:943-959, viii-ix.

13. Vantrappen G, Janssens J, Hellemans J, Ghoos Y. The interdigestive motor complex of normal subjects and patients with bacterial overgrowth of the small intestine. J Clin Invest 1977;59:1158-1166.

14. Quigley EM, Phillips SF, Dent J. Distinctive patterns of interdigestive motility at the canine ileocolonic junction. Gastroenterology 1984;87:836-844.

15. Quigley EM, Borody TJ, Phillips SF, Wienbeck M, Tucker RL, Haddad A. Motility of the terminal ileum and ileocaecal sphincter in healthy man. Gastroenterology 1984;87:857-866.

16. Phillips SF, Quigley EM, Kumar D, Kamath PS. Motility of the ileocolonic junction. Gut 1988;29:390-406.

17. Quigley EM, Phillips SF, Cranley B, Taylor BM, Dent J. Tonic pressures at the canine ileocolonic junction: topography and relationship to phasic motor activity. Am J Physiol 1985;249(3 Pt 1):G350G357.

18. Codling C, O'Mahony L, Shanahan F, Quigley EM, Marchesi JR. A molecular analysis of fecal and mucosal bacterial communities in irritable bowel syndrome. Dig Dis Sci 2010;55:392-397.

19. Swidsinski A, Ladhoff A, Pernthaler A, et al. Mucosal flora in inflammatory bowel disease. Gastroenterology 2002;122:44-54.

20. Wine E, Ossa JC, Gray-Owen SD, Sherman PM. Adherent-invasive Escherichia coli target the epithelial barrier. Gut Microbes 2010;1:80-84.

21. Riordan SM, McIver CJ, Wakefield D, Bolin TD, Duncombe VM, Thomas MC. Small intestinal bacterial overgrowth in the symptomatic elderly. Am J Gastroenterol 1997;92:47-51.

22. Quigley EM, Thompson JS. The motor response to intestinal resection: motor activity in the canine small intestine following distal resection. Gastroenterology 1993;105:791-798.

23. Thompson JS, Quigley EM. Intestinal flora and nutrient absorption after intestinal resection. J Gastrointest Surg 1997;1:554-560.

24. Thompson JS, Quigley EM, Palmer JM, West WW, Adrian TE. Luminal short-chain fatty acids and postresection intestinal adaptation. JPEN J Parenter Enteral Nutr 1996;20:338-343.

25. Thompson JS, Quigley EM, Adrian TE. Qualitative changes in enteric flora and short-chain fatty acids after intestinal resection. Dig Dis Sci 1998;43:624-631.

26. Khan WI, Collins SM. Gut motor function: immunological control in enteric infection and inflammation. Clin Exp Immunol 2006; 143:389-397.

27. Uribe A, Alam M, Johansson O, Midtvedt T, Theodorsson E. Microflora modulates endocrine cells in the gastrointestinal mucosa of the rat. Gastroenterology 1994;107:1259-1269.
28. Kamath PS, Hoepfner MT, Phillips SF. Short-chain fatty acids stimulate motility of the canine ileum. Am J Physiol 1987;253(4 Pt 1):G427-G433.

29. Kamath PS, Phillips SF. Initiation of motility in canine ileum by short chain fatty acids and inhibition by pharmacological agents. Gut 1988;29:941-948.

30. Kamath PS, Phillips SF, Zinsmeister AR. Short-chain fatty acids stimulate ileal motility in humans. Gastroenterology 1988;95:14961502.

31. Kruis W, Azpiroz F, Phillips SF. Contractile patterns and transit of fluid in canine terminal ileum. Am J Physiol 1985;249(2 Pt 1):G264G270.

32. Wedlake L, A'Hern R, Russell D, Thomas K, Walters JR, Andreyev HJ. Systematic review: the prevalence of idiopathic bile acid malabsorption as diagnosed by SeHCAT scanning in patients with diarrhoea-predominant irritable bowel syndrome. Aliment Pharmacol Ther 2009;30:707-717.

33. Rao AS, Wong BS, Camilleri M, et al. Chenodeoxycholate in females with irritable bowel syndrome-constipation: a pharmacodynamic and pharmacogenetic analysis. Gastroenterology 2010;139:1549-1558, e1.

34. Lesniewska V, Rowland I, Laerke HN, Grant G, Naughton PJ. Relationship between dietary-induced changes in intestinal commensal microflora and duodenojejunal myoelectric activity monitored by radiotelemetry in the rat in vivo. Exp Physiol 2006;91:229-237.

35. Pimentel M, Lin HC, Enayati P, et al. Methane, a gas produced by enteric bacteria, slows intestinal transit and augments small intestinal contractile activity. Am J Physiol Gastrointest Liver Physiol 2006; 290:G1089-G1095.

36. Azpiroz F, Malagelada JR. Abdominal bloating. Gastroenterology 2005;129:1060-1078.

37. Bouhnik Y, Flourié B, D'Agay-Abensour L, et al. Administration of transgalacto-oligosaccherides increases fecal bifidobacteria and modifies colonic fermentation metabolism in healthy humans. J Nutr 1997;127:444-448.

38. Jiang T, Savaiano DA. Modification of colonic fermentation by bifidobacteria and $\mathrm{pH}$ in vitro. Impact on lactose metabolism, shortchain fatty acid, and lactate production. Dig Dis Sci 1997;42: 2370-2377.

39. Piche T, Zerbib F, Varannes SB, et al. Modulation by colonic fermentation of LES function in humans. Am J Physiol Gastrointest Liver Physiol 2000;278:G578-G584.

40. Ropert A, Cherbut C, Rozé C, et al. Colonic fermentation and proximal gastric tone in humans. Gastroenterology 1996;111:289-296.

41. Lamine F, Firoamonti J, Bueno L, et al. Nitric oxide released by Lactobacillus farciminis improves TNBS-induced colitis in rats. Scand J Gastroenterol 2004;39:37-45.

42. Verdú EF, Bercik P, Verma-Gandhu M, et al. Specific probiotic therapy attenuates antibiotic induced visceral hypersensitivity in mice. Gut 2006;5 5:182-190.

43. Rousseaux C, Thuru X, Gelot A, et al. Lactobacillus acidophilus modulates intestinal pain and induces opioid and cannabinoid receptors. Nature Med 2007;13:35-37.

44. Collins SM. The immunomodulation of enteric neuromuscular function: implications for motility and inflammatory disorders. Gastroenterology 1996;111:1683-1699. 
45. Resta-Lenert S, Barrett KE. Live probiotics protect intestinal epithelial cells from the effects of infection with enteroinvasive Escherichia coli (EIEC). Gut 2003;52:988-997.

46. Picard C, Fioramonti J, Francois A, Robinson T, Neant F, Matuchansky C. Review article: bifidobacteria as probiotic agents physiological and clinical effects. Aliment Pharmacol Ther 2005; 22:495-512.

47. Qin H, Zhang Z, Hang X, Jiang Y. L. plantarum prevents enteroinvasive Escherichia coli-induced tight junction proteins changes in intestinal epithelial cells. BMC Microbiol 2009;9:63.

48. Asfaha S, MacNaughton WK, Appleyard CB, Chadee K, Wallace JL. Persistent epithelial dysfunction and bacterial translocation after resolution of intestinal inflammation. Am J Physiol Gastrointest Liver Physiol 2001;281:G635-G644.

49. Toskes PP. Bacterial overgrowth of the gastrointestinal tract. Adv Intern Med 1993;38:387-407.

50. Marie I, Ducrotté P, Denis P, Menard JF, Levesque H. Small intestinal bacterial overgrowth in systemic sclerosis. Rheumatology (Oxford) 2009;48:1314-1319.

51. Parodi A, Sessarego M, Greco A, et al. Small intestinal bacterial overgrowth in patients suffering from scleroderma: clinical effectiveness of its eradication. Am J Gastroenterol 2008;103:1257-1262.

52. Krishnamurthy S, Kelly MM, Rohrmann CA, Schuffler MD. Jejunal diverticulosis. A heterogeneous disorder caused by a variety of abnormalities of smooth muscle or myenteric plexus. Gastroenterology 1983;85:538-547.

53. Pimentel M, Chow EJ, Lin HC. Eradication of small intestinal bacterial overgrowth reduces symptoms of irritable bowel syndrome. Am J Gastroenterol 2000;95:3503-3506.

54. Pimentel M, Chow EJ, Lin HC. Normalization of lactulose breath testing correlates with symptom improvement in irritable bowel syndrome: a double-blind, randomized, placebo-controlled study. Am J Gastroenterol 2003;98:412-419.

55. Hasler WL. Lactulose breath testing, bacterial overgrowth, and IBS: just a lot of hot air? Gastroenterology 2003;125:1898-1900.

56. Quigley EM. A 51-year-old with irritable bowel syndrome: test or treat for bacterial overgrowth? Clin Gastroenterol Hepatol 2007;5: 1140-1143.

57. Vanner S. The lactulose breath test for diagnosing SIBO in IBS patients: another nail in the coffin. Am J Gastroenterol 2008;103: 964-965.

58. Vanner S. The small intestinal bacterial overgrowth. Irritable bowel syndrome hypothesis: implications for treatment. Gut 2008;57:13151321.

59. Bratten JR, Spanier J, Jones MP. Lactulose breath testing does not discriminate patients with irritable bowel syndrome from healthy controls. Am J Gastroenterol 2008;103:958-963.

60. Ford AC, Spiegel BM, Talley NJ, Moayyedi P. Small Intestinal bacterial overgrowth in irritable bowel syndrome: systematic review and meta-analysis. Clin Gastroenterol Hepatol 2009;7:1279-1286.

61. Spiegel BM, Chey WD, Chang L. Bacterial overgrowth and irritable bowel syndrome: unifying hypothesis or a spurious consequence of proton pump inhibitors? Am J Gastroenterol 2008;103:2972-2976.

62. Pimentel M, Park S, Mirocha J, Kane SV, Kong Y. The effect of a nonabsorbed antibiotic (rifaximin) on the symptoms of the irritable bowel syndrome: a randomized trial. Ann Intern Med 2006;145:
557-563.

63. Lembo A, Zakko SF, Ferreira NL, et al. Rifaximin for the treatment of diarrhea-associated irritable bowel syndrome: short term treatment leading to long term sustained response. Gastroenterology 2008;134 (suppl 1):A545.

64. Pimentel M, Lembo A, Chey WD, et al. Rifaximin therapy for patients with irritable bowel syndrome without constipation. New Engl J Med 2011;364:22-32.

65. Sharara AI, Aoun E, Abdul-Baki H, Mounzer R, Sidani S, Elhajj I. A randomized double-blind placebo-controlled trial of rifaximin in patients with abdominal bloating and flatulence. Am J Gastroenterol 2006;101:326-333.

66. Yu D, Cheeseman F, Vanner S. Combined oro-caecal scintigraphy and lactulose hydrogen breath testing demonstrate that breath testing detects oro-caecal transit, not small intestinal bacterial overgrowth in patients with IBS. Gut 2011;60:334-340.

67. Spiegel BM. Questioning the bacterial overgrowth hypothesis of IBS: an epidemiologic and evolutionary perspective. Clin Gastroenterol Hepatol Published Online First: 10 Mar 2011. doi: 10.1016/ j.cgh. 2011.02.030

68. Thabane M, Kottachchi DT, Marshall JK. Systematic review and meta-analysis: the incidence and prognosis of post-infectious irritable bowel syndrome. Aliment Pharmacol Ther 2007;26:535-544.

69. Gwee KA, Leong YL, Graham C, et al. The role of psychological and biological factors in post-infective gut dysfunction. Gut 1999;44: 400-406.

70. Spiller RC, Jenkins D, Thornley JP, et al. Increased rectal mucosal enteroendocrine cells $\mathrm{T}$ lymphocytes and increased gut permeability following acute campylobacter enteritis and in post-dysenteric irritable bowel syndrome. Gut 2000;47:804-811.

71. Dunlop SP, Jenkins D, Neal KR, Spiller RC. Relative importance of enterochromaffin cell hyperplasia, anxiety, and depression in postinfectious IBS. Gastroenterology 2003;125:1651-1659.

72. Chadwick VS, Chen W, Shu D, et al. Activation of the mucosal immune system in irritable bowel syndrome. Gastroenterology 2002; 122:1778-1783.

73. Holmén N, Isaksson S, Simrén M, Sjövall H, Ohman L. CD4+ $\mathrm{CD} 25+$ regulatory $\mathrm{T}$ cells in irritable bowel syndrome patients. Neurogastroenterol Motil 2007;19:119-125.

74. Ohman L, Isaksson S, Lundgren A, Simrén M, Sjövall H. A controlled study of colonic immune activity and beta $7+$ blood $\mathrm{T}$ lymphocytes in patients with irritable bowel syndrome. Clin Gastroenterol Hepatol 2005;3:980-986.

75. Barbara G, Stanghellini V, De Giorgio R, et al. Activated mast cells in proximity to colonic nerves correlate with abdominal pain in irritable bowel syndrome. Gastroenterology 2004;126:693-702.

76. Barbara G, Wang B, Stanghellini V, et al. Mast cell-dependent excitation of visceral-nociceptive sensory neurons in irritable bowel syndrome. Gastroenterology 2007;132:26-37.

77. Cenac N, Andrews CN, Holzhausen M, et al. Role for protease activity in visceral pain in irritable bowel syndrome. J Clin Invest 2007;117:636-647.

78. Guilarte M, Santos J, de Torres I, et al. Diarrhoea-predominant IBS patients show mast cell activation and hyperplasia in the jejunum. Gut 2007;56:203-209.

79. Törnblom H, Lindberg G, Nyberg B, Veress B. Full-thickness biop- 
sy of the jejunum reveals inflammation and enteric neuropathy in irritable bowel syndrome. Gastroenterology 2002;123:1972-1979.

80. O'Mahony L, McCarthy J, Kelly P, et al. A randomized, placebo-controlled, double-blind comparison of the probiotic bacteria lactobacillus and bifidobacterium in irritable bowel syndrome (IBS): symptom responses and relationship to cytokine profiles. Gastroenterology 2005;128:541-551.

81. Liebregts T, Adam B, Bredack C, et al . Immune activation in patients with irritable bowel syndrome. Gastroenterology 2007;132: 913-920.

82. Dinan TG, Quigley EM, Ahmed SM, et al. Hypothalamic-pituitary-gut axis dysregulation in irritable bowel syndrome: plasma cytokines as a potential biomarker? Gastroenterology 2006;130:304-311.

83. Collins SM. A case for an immunological basis for irritable bowel syndrome. Gastroenterology 2002;122:2078-2080.

84. Spiller RC. Role of nerves in enteric infection. Gut 2002;51:759-762.

85. Gonsalkorale WM, Perrey C, Pravica V, Whorwell PJ, Hutchinson IV. Interleukin 10 genotypes in irritable bowel syndrome: evidence for an inflammatory component? Gut 2003;52:91-93.

86. van der Veek PP, van den Berg M, de Kroon YE, Verspaget HW, Masclee AA. Role of tumor necrosis factor-alpha and interleukin-10 gene polymorphisms in irritable bowel syndrome. Am J Gastroenterol 2005;100:2510-2516.

87. Schoepfer AM, Schaffer T, Seibold-Schmid B, Müller S, Seibold F. Antibodies to flagellin indicate reactivity to bacterial antigens in IBS patients. Neurogastroenterol Motil 2008;20:1110-1118.
88. Ivison SM, Steiner TS. Anti-flagellin antibodies in irritable bowel syndrome: another attack on our commensals? Neurogastroenterol Motil 2008;20:1081-1085.

89. Langhorst J, Junge A, Rueffer A, et al. Elevated human beta-defensin-2 levels indicate an activation of the innate immune system in patients with irritable bowel syndrome. Am J Gastroenterol 2009; 104:404-410.

90. Brint EK, MacSharry J, Fanning A, Shanahan F, Quigley EM. Differential expression of toll-like receptors (TLRs) in patients with irritable bowel syndrome. Am J Gastroenterol 2011;106:329-336.

91. Bradley HK, Wyatt GM, Bayliss CE, Hunter JO. Instability in the faecal flora of a patient suffering from food-related irritable bowel syndrome. J Med Microbiol 1987;23:29-32.

92. Si JM, Yu YC, Fan YJ, Chen SJ. Intestinal microecology and quality of life in irritable bowel syndrome patients. World J Gastroenterol 2004;10:1802-1805.

93. Malinen E, Rinttilä T, Kajander K, et al. Analysis of the fecal microbiota of irritable bowel syndrome patients and healthy controls with real-time PCR. Am J Gastroenterol 2005;100:373-382.

94. Mättö J, Maunuksela L, Kajander K, et al. Composition and temporal stability of gastrointestinal microbiota in irritable bowel syndrome - a longitudinal study in IBS and control subjects. FEMS Immunol Med Microbiol 2005;43:213-222.

95. Kassinen A, Krogius-Kurikka L, Mäkivuokko H, et al. The fecal microbiota of irritable bowel syndrome patients differs significantly from that of healthy subjects. Gastroenterology 2007;133:24-33. 